\title{
Ulubey ilçesinde (Ordu) MM 106 ve M 9 anaçları üzerindeki 'Granny Smith' elma çeşidinin ilk yıllar verim ve pomolojik özellikleri*
}

\author{
Melek ŞENSOY', Saim Zeki BOSTAN² \\ 1Ordu İl Tarım ve Orman Müdürlüğü, Ordu \\ ${ }^{2}$ Ordu Üniversitesi Ziraat Fakültesi Bahçe Bitkileri Bölümü, Ordu
}

* $\mathrm{Bu}$ çalışma Ordu Üniversitesi Fen bilimleri Enstitüsü Bahçe Bitkileri Anabilim Dalı'nda kabul edilen yüksek lisans tezinden hazırlanmıştır. Makale 26-28 Ekim 2017 tarihlerinde Tokat"ta düzenlenen "II Ulusal Yumuşak Çekirdekli Meyve Türleri Sempozyumu"nda poster olarak sunulmuştur.

Alınış tarihi: 17 Ekim 2018, Kabul tarihi: 13 Aralık 2018

Sorumlu yazar: Saim Zeki BOSTAN, e-posta: szbostan@hotmail.com

\section{Öz}

Bu çalıșma Ordu ili Ulubey ilçesinde MM 106 ve M 9 anaçları üzerine aşılanmış 'Granny Smith' elma çeșidi ile 2009 yılında kurulmuş 2 farklı rakımdaki elma bahçelerinde yürütülmüştür. Çalışmada ağaçların ortalama verim ve kümülatif verimleri için 20102013 yılları, pomolojik kriterler için de 2010 ve 2011 yılları değerlendirilmiştir. Çalışma sonucunda, ortalama verimin $1.363 \mathrm{~kg} /$ ağaç (MM 106 anacı üzerinde) ile $2.588 \mathrm{~kg} /$ ağaç (M 9 anacı üzerinde) arasında; kümülatif verimin de $5.453 \mathrm{~kg} /$ ağaç (MM 106 anacı üzerinde) ile $10.351 \mathrm{~kg} / \mathrm{ağaç} \mathrm{(M} 9$ anacı üzerinde) arasında değiştiği belirlenmiştir. Diğer taraftan iki yıllık ortalama değerlere göre, meyve ağırlığı 158.11 g (MM 106) - 191.10 g (M 9), meyve boyu $64.30 \mathrm{~mm}$ (MM 106) - $69.62 \mathrm{~mm}$ (M 9), meyve çapı 71.33 mm (MM 106) - 75.77 mm (M 9), meyve eti sertliği $8.19 \mathrm{~kg} / \mathrm{cm}^{2}$ (MM 106) - $8.38 \mathrm{~kg} / \mathrm{cm}^{2}(\mathrm{M}$ 9) ve SÇKM değeri de \%10.68 (MM 106) - \% 11.53 (M 9) arasında ölçülmüştür.

Anahtar kelimeler: Elma, Granny Smith, anaç, verim, kalite, Ordu

The first years yield and pomological traits of 'Granny Smith' apple cultivar grafted on MM 106 and $M 9$ rootstocks in Ulubey County (Ordu province of Turkey)

\section{Abstract}

This study was carried out in apple orchards established in 2009 with 'Granny Smith' cultivar grafted on MM 106 and M 9 rootstocks at two different altitudes in Ulubey County (Ordu province of Turkey). The data of 2010-2013 years were used for average yield and cumulative yield, and 2010 and
2011 years data were used for pomological traits. As a result of this study, The average yield varied from $1.363 \mathrm{~kg} /$ tree (on MM 106) to $2.588 \mathrm{~kg} /$ tree (on M 9), and the cumulative yield varied between 5.453 $\mathrm{kg} /$ tree (on MM 106) and $10.351 \mathrm{~kg} /$ tree (on M 9). On the other hand, according to the average values of experimental years, fruit weight ranged from 158.11 g (MM 106) to $191.10 \mathrm{~g}$ (M 9), fruit length ranged from $64.30 \mathrm{~mm}$ (MM 106) to $69.62 \mathrm{~mm}$ (M 9), fruit diameter ranged $71.33 \mathrm{~mm}$ (MM 106) to $75.77 \mathrm{~mm}$ (M 9), fruit flesh firmness ranged from $8.19 \mathrm{~kg} / \mathrm{cm}^{2}$ (MM 106) to $8.38 \mathrm{~kg} / \mathrm{cm}^{2}$ (M 9) and total soluble solid contents ranged from $10.68 \%$ (MM 106) to $11.53 \%$ (M 9).

Key words: Apple, Granny Smith, rootstock, yield, quality, Ordu

\section{Giriş}

Türkiye farklı iklim ve çeşitli toprak yapılarına sahip olduğu için birçok meyve türünün anavatanı olmuş ya da anavatanları arasında yer almıştır. Ülkemizde yetiştirilen meyve türlerinin bir kısmı kendiliğinden var olmuşken, bir kısmı ise farklı ülkelerden veya bölgelerden ülkemize taşınmıştır. Birçok meyve türünün gen merkezi olan Anadolu elmanın da gen merkezi ve doğal yayılma alanları arasında sayılmaktadır (Özbek, 1978). Ülkemizin hemen her yerinde çok eski yıllardan beri elma yetiştirilmektedir. Fakat en uygun kültür merkezleri yabanisinin yayılma alanlarına paralel olarak Kuzey Anadolu'da bulunmaktadır. Kuzey Anadolu, Karadeniz kıyı bölgesi ile İç Anadolu ve Doğu Anadolu yaylaları arasındaki geçit bölgeleri ve son yıllarda güneyde göller bölgesi elmanın önemli yetiştiricilik alanlarını oluşturmaktadır (Anonim, 
2001). Türkiye dünya elma üretiminde 2016 yılı verilerine göre 2925828 tonluk üretimiyle Çin, A.B.D. ve Polonya'nın ardından 4. sırada yer almıștır (Anonim, 2018a). Ülkemizde ve en fazla üretilen çeşitler sırasıyla Starking, Golden, diğer grup, Amasya ve Granny Smith olmuştur. Ordu ilinde 5 930 ton'luk (\% 0.20) üretimde en fazla payı $(\%$ 88.47) diğer gruptaki elmalar oluştururken, bu grubu sirasiyla Golden, Granny Smith ve Starking çeşitleri izlemiştir (Anonim, 2018b). Elma, farklı ekoloji ve toprak yapılarına uygun çeşit ve anaç zenginliğine sahip olması nedeniyle diğer bir çok meyve türüne göre daha geniş bir yelpazede yetiştirilebilmektedir. Bununla birlikte üretimin belirli bölgelerde yoğunlaştığı görülmektedir. Geniş bir alanda yetiștiriciliği yapılan elmada, uluslararası alanda rekabet oldukça fazla olduğundan pazar yakalama şansı çok düşüktür. Bu sebeple en iyi çeşidi en düşük maliyetle üretmek zorunludur (Özongun ve ark., 2014). Modern meyveciliğin gerekleri olan her yıl düzenli ürün alma, ağaçların erken verime yatması ve birim alana daha fazla ağaç kullanılarak verimin artırılması, budama ve seyreltmenin daha kolay ve ekonomik yapılabilmesi, meyve iriliği ve renk yönünden daha kaliteli ürün elde edilmesi, bodur elma anaçları kullanılarak gerçekleştirilmektedir (Soylu ve ark., 2003). Ülkemizde, son yıllarda elma yetiştiriciliğinin daha teknik ve bilinçli yapılması, bodur ve yeni bodur elma çeşitlerinin üretimde yer alması ve üretimin modern koşullarda gerçekleştirilmesi nedeniyle hem ağaç sayısı hem de üretim miktarında artış olmuştur. Ülkemizde klon anaçları ile ilgili verim denemelerinde bazı standart elma çeşitlerinde en yüksek verim M 9 ve MM 106 anaçlarından elde edilmiş ve bu anaçlar ülkemiz için de tavsiye edilmiştir. Bunun yanında, Granny Smith çeşidinin farklı anaçlar üzerindeki verim ve kalite özelliklerinin araştırıldığı bir çalışmada, gerek birim alana düșen verim ile verimin bir örnekliği ve gerekse erken verime yatma yönünden M 9 anacının uygun olduğu ve bunu da MM 106 anacının izlediği görülmüştür (Burak ve ark., 1997). Bu çalıșma ile de M 9 ve MM 106 anaçları üzerine aşılanmış 'Granny Smith' elma çeşidinin Ordu ili Ulubey ilçesinde verim ve kalite özelliklerinin incelenmesi amaçlanmıştır.

\section{Materyal ve Yöntem}

\section{Materyal}

Ordu merkeze $22 \mathrm{~km}$ mesafede olan Ulubey ilçesi, Ordu-Sivas karayolu üzerinde olup rakımı 586 m'dir. Dağlık bir yapıya sahip olan ilçenin kuzey batısında
Perşembe, batısında Gürgentepe, güneyinde Mesudiye, güney batısında Gölköy, güney doğusunda Kabadüz ilçeleriyle, kuzeyinde Altınordu ilçesi bulunmaktadır. Bu çalışma Ordu ili, Ulubey ilçesinde M 9 ve MM 106 anaçları üzerine aşılı 'Granny Smith' elma çeşidi ile İlçe Tarım ve Orman Müdürlüğü tarafından sağlanan fidanlarla, 2009 yılı Mart ayında tesis edilmiş iki farklı rakımdaki elma bahçelerinde yürütülmüştür. Deneme süresince gübreleme ve ilaçlama işlemleri iki bahçede de aynı şekilde uygulanmıştır. Budama işlemleri tekniğine uygun şekilde yapılmıştır. Sulama yapılmamıştır.

1. bahçe Ulubey ilçesi Aydınlar köyünde bulunup Ordu merkeze uzaklığı 17 km, rakımı 250-260 m ve kuzey-batıya doğru \% 50 meyillidir. Toprak yapısı killi-tınlı ve organik madde oranı (\% 3.61) orta düzeydedir. Hafif asit karakterde olup, pH 6.5'tir. MM 106 anacı üzerine aşılı 150 adet 'Granny Smith' elma fidanından kurulmuştur.

2. Bahçe Ulubey ilçesi Kumrulu köyünde Ordu merkeze uzaklığı 19 km, rakımı 436 m ve güneybatıya doğru \% 5 meyillidir. Toprak yapısı killi-tınlı ve organik madde oranı (\% 3.06) orta düzeydedir. Hafif asit karakterde olup, pH 6.4'tür. M 9 anacı üzerine aşılı 250 adet 'Granny Smith' elma fidanından kurulmuştur.

\section{Yöntem \\ İncelenen özellikler}

Her bahçedeki 3'er ağaçtan tesadüfen alınan 10'ar meyvede 2010 ve 2011 yıllarında (dikimden sonraki 1. ve 2. yıllarda) iki yıl süreyle meyve ağırlığı, meyve boyu, meyve çapı, meyve şekil indeksi, meyve hacmi, meyve eti sertliği, kabuk kalınlığı, meyve sapı uzunluğu, meyve sapı kalınlığı, sap çukuru genişliği, sap çukuru derinliği, çiçek çukuru genişliği, çiçek çukuru derinliği, çekirdek evi uzunluğu, çekirdek evi genişliği, çekirdek sayısı, çekirdek ağırlığı, çekirdek eni, çekirdek boyu, çekirdek kalınlığı, meyve zemin rengi, meyve üst rengi, meyve eti rengi, suda çözünür kuru madde miktarı (SÇKM), pH, titre edilebilir asit miktarı; yaprak örneklerinde yaprak eni, yaprak boyu, yaprak sapı uzunluğu, yaprak sapı kalınlığı ve yaprak alanı ile 11.04.2011-17.12.2011 tarihleri arasındaki gövde çapı gelişimi (seçilen ağaçlarda vejetasyon dönemi başı ve sonu itibariyle aşı yerinin $5 \mathrm{~cm}$ üzerinden), sürgün çapı gelişimi ve sürgün boyu gelişimi (seçilen ağaçlarda vejetasyon dönemi başı ve sonu itibariyle seçilen 4'er sürgünde) belirlenmiştir. Ağaçların toplam verimleri 20102013 yılları arasında (dikimden sonraki 1.-4. yıllar arasında) olmak üzere 4 yıllık olarak belirlenmiştir. 


\section{Deneme deseni ve istatistiki analizler}

Deneme tesadüf blokları deneme desenine göre 3 tekerrürlü olarak yürütülmüş olup, her tekerrürde de 3'er ağaç seçilmiştir. Denemede ortalama verim için 2010-2013 yılları kalite parametreleri için de 2010 ve 2011 yılları verileri değerlendirilmiştir. İstatistiksel analizler JMP11 programında yapılmıştır. Ortalamalar arasındaki farklılıklar LSD testi ile belirlenmiştir.

\section{Bulgular ve Tartışma}

'Granny Smith' elma çeşidinde ortalama verimin ve kümülatif verimin anaçlara göre değişimi belirlemek için yapılan varyans analizi sonucunda, verimin $(p<0.01)$ ve kümülatif verimin $(p<0.05)$ anaçlara göre önemli çıktığı belirlenmiştir. 'Granny Smith' elma çeşidinde ortalama verim $1.363 \mathrm{~kg} /$ ağaç (MM 106 anacı üzerinde) ile $2.588 \mathrm{~kg} /$ ağaç (M 9 anacı üzerinde), kümülatif verim de $5.453 \mathrm{~kg} /$ ağaç (MM 106 anacı üzerinde) ile $10.351 \mathrm{~kg} /$ ağaç (M 9 anacı üzerinde) arasında değiștiği görülmüştür (Çizelge 1).

Çizelge 1. 'Granny Smith' elma çeşidinde farklı anaçlar üzerindeki ortalama (kg/ağaç) ve kümülatif verim (kg/ağaç) değerleri

\begin{tabular}{lccc}
\hline Verim (kg/ağaç) & M M 106 & M 9 & LSD \\
\hline Ortalama (2010-2013) & $1.363 \mathrm{~b}$ & $2.588 \mathrm{a}$ & 0.390 \\
Kümülatif (2010-2013) & $5.453 \mathrm{~b}$ & $10.351 \mathrm{a}$ & 3.582 \\
\hline
\end{tabular}

'Granny Smith' elma çeşidinde farklı anaçlar üzerinde meyve kalite özelliklerine ait ortalama değerler Çizelge 2'de sunulmuştur. Çizelgeye göre, önemli pomolojik özelliklerden olan meyve ağırlığı $(\mathrm{p}<0.05)$, meyve boyu $(\mathrm{p}<0.05)$, meyve çapı $(\mathrm{p}<0.05)$, meyve hacmi $(\mathrm{p}<0.05)$, sap çukuru derinliği $(p<0.01)$, çiçek çukuru derinliği $(p<0.05)$, çekirdek evi genişliği $(\mathrm{p}<0.01)$, çekirdek sayısı $(\mathrm{p}<0.01)$, çekirdek sayısı $(\mathrm{p}<0.05)$, suda çözünür kuru madde oranı $(\mathrm{p}<0.01)$, meyve eti ' $a$ ' değeri $(p<0.01)$, meyve zemini 'L' değeri $(p<0.05)$ ve meyve zemini ' $b$ ' değeri $(p<0.01)$ M 9 anacı üzerindeki meyvelerde, sadece meyve sapı uzunluğu $(\mathrm{p}<0.01)$ MM 106 anacı üzerindeki meyvelerde daha fazla olmuştur. Diğer özelliklerin anaçlara göre değişimi önemli çıkmamıştır. M 9 anacı üzerindeki meyveler 191.1 g gelirken, MM 106 anacı üzerindeki meyveler 158.2 g gelmiştir. Ağaçlarda 11.04.2011 - 17.12.2011 tarihleri arasındaki gelişim farkı, her iki tarihte belirlenen değerlerin birbirinden çıkarılması ile belirlenmiştir. Belirtilen tarih aralığında en fazla gövde çapı, sürgün çapı ve sürgün boyu gelişimi MM 106 anacı üzerinde belirlenmiştir $(\mathrm{p}<0.05)$ (Çizelge 3). Çalışmanın yürütüldüğü 2 farklı rakımda bulunan
Çizelge 2. 'Granny Smith' elma çeşidinde farklı anaçlar üzerinde pomolojik özelliklere ait ortalama değerler

\begin{tabular}{|c|c|c|c|}
\hline Özellikler & MM 106 & M 9 & LSD \\
\hline Yaprak eni $(\mathrm{mm})$ & 46.4 & 46.2 & \\
\hline Yaprak Boyu (mm) & 81.8 & 83.5 & \\
\hline Yaprak Sap Uzunluğu (mm) & 25.6 & 26.3 & \\
\hline Yaprak Sap Kalınlığ 1 (mm) & 1.5 & 1.7 & \\
\hline Yaprak Alanı $\left(\mathrm{cm}^{2}\right)$ & 29.1 & 28.8 & \\
\hline Meyve Ağırlığı (g) & $158.2 \mathrm{~b}$ & 191.1 a & 23.6 \\
\hline Meyve Boyu (mm) & $64.3 \mathrm{~b}$ & $69.6 \mathrm{a}$ & 4.3 \\
\hline Meyve Çapı (mm) & $71.3 \mathrm{~b}$ & 75.8 a & 3.4 \\
\hline Meyve Șekil İndeksi & 0.90 & 0.92 & \\
\hline Meyve Hacmi (ml) & $203.2 \mathrm{~b}$ & 244.9 a & 34.8 \\
\hline Meyve Sap Uzunluğu (mm) & $19.4 \mathrm{a}$ & $16.9 \mathrm{~b}$ & \\
\hline Meyve Sap Kalınlığı (mm) & 1.91 & 2.09 & \\
\hline Meyve Eti Sertliği $\left(\mathrm{kg} / \mathrm{cm}^{2}\right)$ & 8.19 & 8.38 & \\
\hline Meyve Kabuk Kalınlığı (mm) & 0.31 & 0.27 & \\
\hline Sap Çukuru Genișliği (mm) & 25.74 & 26.36 & \\
\hline Sap Çukuru Derinliği (mm) & $9.6 \mathrm{~b}$ & $12.0 \mathrm{a}$ & 0.4 \\
\hline Çiçek Çukuru Genişliği (mm) & 23.92 & 24.66 & \\
\hline Çiçek Çukuru Derinliği (mm) & $7.5 \mathrm{~b}$ & $9.2 \mathrm{a}$ & 0.7 \\
\hline Çekirdek Evi Genişliği (mm) & $18.2 \mathrm{~b}$ & $20.6 \mathrm{a}$ & 4.3 \\
\hline Çekirdek Evi Boyu (mm) & 21.25 & 21.26 & \\
\hline Çekirdek Sayısı & $4.9 \mathrm{~b}$ & $6.9 \mathrm{a}$ & 1.2 \\
\hline Çekirdek Ağırlığı (g) & $0.4 \mathrm{~b}$ & $0.5 \mathrm{a}$ & 0.09 \\
\hline Çekirdek Eni (mm) & 4.66 & 4.75 & \\
\hline Cekirdek Boyu 8mm) & 7.63 & 7.79 & \\
\hline Çekirdek Kalınlığı (mm) & 3.20 & 3.31 & \\
\hline Meyve Eti Rengi (L) & 75.16 & 76.54 & \\
\hline Meyve Eti Rengi (a) & $-6.8 b$ & $-5.7 \mathrm{a}$ & 0.3 \\
\hline Meyve Eti Rengi (b) & 14.53 & 13.52 & \\
\hline Meyve Zemin Rengi (L) & $52.3 \mathrm{~b}$ & 53.7 a & 1.3 \\
\hline Meyve Zemin Rengi (a) & -17.22 & -17.53 & \\
\hline Meyve Zemin Rengi (b) & $24.9 \mathrm{~b}$ & $26.7 \mathrm{a}$ & 0.7 \\
\hline Meyve Üst Rengi (L) & 55.57 & 54.53 & \\
\hline Meyve Üst Rengi (a) & -15.99 & -13.77 & \\
\hline Meyve Üst Rengi (b) & 26.32 & 26.45 & \\
\hline SÇKM (\%) & $10.7 \mathrm{~b}$ & $11.6 \mathrm{a}$ & 0.3 \\
\hline $\mathrm{pH}$ & 3.39 & 3.35 & \\
\hline Asitlik (\%) & 0.84 & 0.80 & \\
\hline
\end{tabular}

Çizelge 3. 'Granny Smith' elma çeşidinde farklı anaçlar üzerindeki gövde ve sürgün gelişimi değerleri

\begin{tabular}{lccc}
\hline Özellikler & MM 106 & M 9 & LSD \\
\hline Gövde çapı gelişimi (mm) & 8.583 & 5.817 & \\
Sürgün çapı gelişimi (mm) & 3.263 & 1.823 & \\
Sürgün boyu gelişimi (cm) & $56.412 \mathrm{a}$ & $33.160 \mathrm{~b}$ & 179.251 \\
\hline
\end{tabular}

çiçeklenme başlangıcı, tam çiçeklenme, çiçeklenme sonu ve hasat başlangıcı tarihlerinin birbirine çok yakın olduğu, gelişmelerin düşük rakımlı olan 1 . bahçeden başlayarak 1-2 gün aralıklarla birbirini takip ettiği gözlemlenmiștir. Yaprak dökümü tarihi ise bu durumun tersine, yüksek rakımlı olan 2 . bahçede 1-2 gün daha erken olmuştur. 2011 yılı ilkbahar döneminde havaların önceki yıllara göre daha soğuk geçmiş olmasından dolayı çiçeklenme geç başlamıştır. Yalova koşullarında yapılan bir çalışmada da dikimden sonraki 2.-11. yıllar arası dekara kümülatif verim değerlerinin M 9 anacına aşılı 'Granny Smith' elma çeşidinde, MM 106, MM 
Çizelge 4. Farklı anaçlar üzerine aşılı 'Granny Smith' elma çeşidinde fenolojik gözlemler

\begin{tabular}{lcc}
\hline Fenolojik Özellikler & 1. Bahçe (MM106) & 2.Bahçe (M9) \\
\hline Tomurcuk Kabarması & $07-11 / 04$ & $08-12 / 04$ \\
Tomurcuk Patlaması & $06-14 / 05$ & $07-15 / 05$ \\
Çiçeklenme Başlangıcı & $12-16 / 05$ & $13-17 / 05$ \\
Tam Çiçeklenme & $18-20 / 05$ & $19-21 / 05$ \\
Çiçeklenme Sonu & $26-28 / 05$ & $27-29 / 05$ \\
Hasat Başlangıcı & $21-23 / 10$ & $22-24 / 10$ \\
Yaprak Dökümü & $20-22 / 12$ & $18-20 / 12$ \\
Çiçeklenme-Hasat Gün & $155-158$ & $155-158$ \\
\hline
\end{tabular}

111 ve çöğür anaçlara aşılı olanlara göre daha fazla olduğu (Burak ve ark.,1997); Pozantı'da yapılan bir çalışmada 5 yaşındaki ağaçlarda ağaç başına verimin MM 106 anacına aşılı 'Granny Smith' elma çeșidinde (20.18 kg) M 9 anacına aşılı olana göre (11.18 kg) daha fazla fakat dekara verimin M 9 anacına aşılı olanda (927.7 kg) diğerine göre $(827.5 \mathrm{~kg}$ ) daha fazla olduğu (Küden ve ark., 1992); Samsun ekolojisinde dikimden sonraki 2. ve 3. yılların ortalaması olarak, ağaç başına verimin MM 106 anacına aşılı 'Granny Smith' elma çeşidinde $8.817 \mathrm{~kg}$, M 9 üzerinde ise $7.069 \mathrm{~kg}$ olduğu (Bilgener ve ark., 2003); bu çalışmanın 2002-2006 yıllarını kapsan diğer bölümünde ağaç ve kümülatif verim değerlerinin MM 106 üzerinde M 9 üzerindekine göre daha fazla olduğu (Kaplan ve ark., 2007); Ordu ekolojisinde M 9 anacı üzerinde farklı çeşitlerin performanslarının araştırıldığı bir çalışmada dikimden sonraki 4. yılda 'Granny Smith' elma çeşidinde ağaç başına verimin 11.02 kg olduğu (Öztürk ve ark., 2016) ve Samsun ekolojisinde yapılan bir diğer çalışmada da M 9 anacına aşılı Granny Smith elmasında 5. ve 6. yıllar verim ortalamasının $11.30 \mathrm{~kg}$ olduğu belirtilmiştir (Aksoy, 2017). Farklı ekolojilerde yapılan çalışmaların sonuçlarının da farklı olduğu gözükmektedir. Çalışmamızda belirlediğimiz gerek ağaç başına verim değerleri gerekse kümülatif verim değerleri literatür bulgularından daha düşük çıkmıştır.

\section{Sonuç ve Öneriler}

Çalışmanın yürütüldüğü ilçede farklı iki loksayonda bulunan biri M9 anacına aşıll, diğeri de MM106 anacına aşılı Granny Smith elmasıyla kurulu olan bahçeler dikkate alındığında; verim bakımından M 9 anacının MM 106 anacına göre daha iyi sonuç verdiğini söyleyebiliriz. Meyve ağırlığı, meyve iriliği ve SÇKM yönünden de M9 anacına aşılı ağaçlar iyi sonuç vermiştir. Kalite parametreleri yönünden diğer ekolojilerde yapılan çalışma sonuçları karşılaştırıldığında çok önemli farklılıkların olmadığı söylenebilse de verim değerlerinin daha düşük düzeyde olduğu görülmüştür. Bu durumda yörede bu çalışmanın devam ettirilmesi ve farklı lokasyonlarda ve uzun yıllar sonuçlarının alınarak genişletilmesinde yarar görülmektedir.

\section{Kaynaklar}

Aksoy, B., 2017. Çarşamba'da M9 anacı üzerine aşılı bazı elma çeșitlerinin (Granny Smith, Royal Gala ve Galaxy Gala) verim ve bazı meyve kalite özelliklerinin incelenmesi. Ordu Üniversitesi Fen Bilimleri Enstitüsü Bahçe Bitkileri Anabilim Dalı Yüksek Lisans Tezi. Ordu, $42 \mathrm{~s}$.

Anonim, 2001. Bitkisel Üretim (Meyvecilik) Özel İhtisas Komisyonu Raporu. Devlet Planlama Teşkilatı, Ankara.

Anonim, 2018a. FAOSTAT. http://www.fao.org/faostat/ en/\#data/QC

Anonim, 2018b.. TÜİK. https://biruni.tuik.gov.tr/bitkisel

Bilgener, Ş., Akbulut, M., Kaplan, N., 2003. Samsun koşullarında elma yetiştiriciliğinde anaç $\mathrm{x}$ çeşit $\mathrm{x}$ dikim sıklığı kombinasyonlarının saptanması üzerinde bir araştırma. Türkiye IV. Ulusal Bahçe Bitkileri Kongresi, Antalya.

Burak, M., Büyükyılmaz, M., Öz, F., 1997. Granny Smith elma çeşidinin farklı anaçlar üzerindeki verim ve kalite özelliklerinin belirlenmesi. Yumuşak Çekirdekli Meyveler Sempozyumu, Yalova.

Kaplan, N., Bilgener, Ş., Akbulut, M., Koç, A., 2007. Samsun koşullarında elma yetiştiriciliğinde anaç $\mathrm{x}$ çeşit $\mathrm{x}$ dikim sıklığı kombinasyonlarının meyve verim ve kalitesi üzerine etkilerinin araştırılması. Türkiye V. Ulusal Bahçe Bitkileri Kongresi, Erzurum.

Küden, A., Gezerel, Ö., Kaşka, N., 1992. Farklı klonal ve çöğür anaçları üzerine aşılı bazı elma çeşitlerinin bitki besin madde içerikleriyle verim düzeyleri arasındaki ilişkiler. Türkiye I. Ulusal Bahçe Bitkileri Kongresi, Bornova, İzmir.

Özbek, S., 1978. Özel Meyvecilik. Çukurova Üniversitesi Ziraat Fakültesi, No: 128, Ankara, 485s.

Özongun, Ş., Dolunay, E.M., Öztürk, G., Pektaş, M., 2014. Eğirdir (Isparta) şartlarında bazı elma çeşitlerinin performansları. Meyve Bilimi, 1(2):21-29.

Öztürk, B., Uzun, S., Bektaş, E., Yarılgaç, T., Karakaya, M., Karakaya, M., Gün, S., Turga, E., 2016. M9 Anacı üzerine aşılı bazı elma çeşitlerinin Ordu ilinde verim ve kalite özelliklerinin belirlenmesi. Bahçe 45: 492-497.

Soylu, A., Ertürk, Ü., Mert, C., Öztürk, Ö., 2003. MM 106 anacı üzerine aşılı elma çeşitlerinin Görükle koşullarındaki verim ve kalite özelliklerinin incelenmesi-II, Uludağ Üniversitesi Ziraat Fakültesi Dergisi, 17(2): 57-65. 